\title{
蹴り上げと蹴り下げ速度の異なるモノフィンの推進カ
}

\section{Propulsive Force of Monofin with Different Kicking Speed between Upstroke and Downstroke}

\author{
O正 羽二生 稔大（秋田大院） \\ 高木 英樹（筑波大院） \\ 正長谷川裕晃（秋田大院） \\ 下門 洋文 (筑波大) \\ Toshihiro HANIU, Akita University, 1-1 Tegata gakuen-machi, Akita-shi, Akita, 010-0852 \\ Hiroaki HASEGAWA, Akita University, 1-1 Tegata gakuen-machi, Akita-shi, Akita, 010-0852 \\ Hideki TAKAGI, University of Tsukuba, 1-1-1 Tennodai, Tsukuba, Ibaraki 305-8577 \\ Hirofumi SHIMOJO, University of Tsukuba, 1-1-1 Tennodai, Tsukuba, Ibaraki 305-8577

\begin{abstract}
It is known that the finswimming is fast swimming style. The actual motion of a monofin is obviously unsteady. That is, the unsteady forces must also be considered to estimate the propulsive force of a monofin. The aim of this study was to elucidate the relationship between propulsive forces and unsteady flow structure of monofin with different kicking speed in the kick-up (upstroke) and kick-down (downstroke). Experiments were performed in a circulating water channel, the kick-up and kick-down motions of the monofin were operated by a drive unit using a stepping motor. The oscillating (pitching) center in the motion was set at $-20^{\circ}\left(0^{\circ}\right.$ being the horizontal plane) and the pitching angle was $\pm 20^{\circ}$. The peak value of propulsive force during one kick stroke becomes larger with increasing down-kick speed, and the propulsive force is strongly associated with kicking speed during downstroke. Because, the strong vortex ring is generated near the monofin with increasing down-kick speed.
\end{abstract}

Key Words:, Propulsive Force, Vortex, Unsteady Flow, PIV, Monofin

\section{1. 緒言}

フィンスイミングは遊泳速度の速さが魅力の競技である。 特に, 一枚のフィンを足に装着するモノフィンは, 人が動力 を使わずに, 最も速く泳ぐことのできる泳法として知られて いる，例えば，水中を潜水して $50 \mathrm{~m}$ 泳ぐアプニアという競 技では秒速 $3.5 \mathrm{~m}$ を越え, クロール泳法の約 1.5 倍の速度に も達する，近年，モノフィンに関する研究が行われている。 モノフィンの泳ぎを見てみると,フィンは明らかに非定常な 動きをしており，イルカなどの水棲生物と同様に, 非定常流 体力を効果的利用していることが考えられる.Imamura らは ステレオ PIV(Particle Images Velocimetry)計測を用いて，モノ フィン後流の渦構造を三次元的に構築し, 推進力との比較を 行った (1). 田村らはモノフィンの取り付け角に着目し，水平 に取り付けるよりもマイナス方向に取り付けた方が, 効率よ く推進力を得られることを示した(2). また，モノフインスイ マーは，跍り上げと蹴り下げ速度を変化させて泳いでいる.

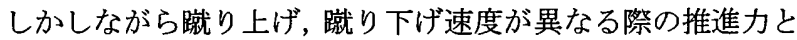
流れ場については明らかになっていない。

そこで, 本研究では蹴り上げと蹴り下げ速度を変化させた 際に生じる推進力と流れ場の関倸を明らかにすることを目 的とし, 実験を行った. 流れ場の三次元構造を調べるために, 複数断面についてスキャニングするステレオ PV 計测を適 用することで構築した。

\section{2. 実験装置および方法}

実験で使用したモノフィンを図 1 に示す. 形状は翼弦長 $c=$ $360 \mathrm{~mm}$, 翼幅 $b=320 \mathrm{~mm}$ となっている．また，弾性を高め るために, フィンの付け根から先端に向けて薄くなる積層構 造である. 実験で使用した測定部を図 2 に示す. 実験は測定 部が長さ $4.6 \mathrm{~m}$, 幅 $2.0 \mathrm{~m}$, 高さ $1.2 \mathrm{~m}$ を有する筑波大学の回 流水槽で行った. 座標系はフィンの振動軸の中心を原点とし て, 主流方向を $x$, スパン方向を $y$, 高さ方向 $z$ とした. フィ ンは, 駆動装置上部に取り付けたステッピングモータによっ て振動させた. 本実験では振動数 $f$ は実際の泳者の無次元振 動数 ${ }^{(3)}$ を参考に, $f=0.67 \mathrm{~Hz}$ とし, 振幅は $\alpha= \pm 20^{\circ}$ とした. また，実際モノフィンは下向きに取り付けられているため, 振動中心角は下向きの $\alpha_{c}=-20^{\circ}$ で行った. また, 蹴り上げ と踤り下げ速度を変化させた際の推進力と流れ場の変化を 調べるために 5 種類の振動を与えた．本論文では，一定速度
の場合と推進力が増加した踕り下げが速い場合について説 明する. 図 3 にフィンの迎角変化を示す. 推進力は駆動装置 に取り付けたロードセルによって測定した．駆動装置はレー ルの上に乗せられており， $x$ 方向にスライド可能である．ま た, 同時にポテンショメータによってフィンのピッチ角度も 測定した．流れ場の測定にはステレオ PIV(Particle Images Velocimetry)計測を用いた。PIV 計測システムは, 光源に Nd-YAG レーザ, CCD カメラで構成される. 撮影タイミング

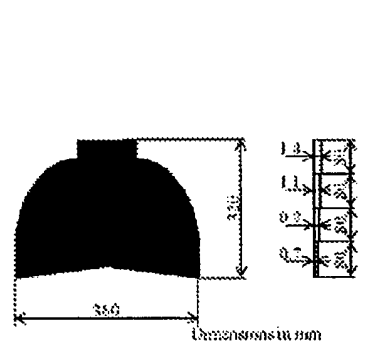

Fig. 1 The shape of the Monofin

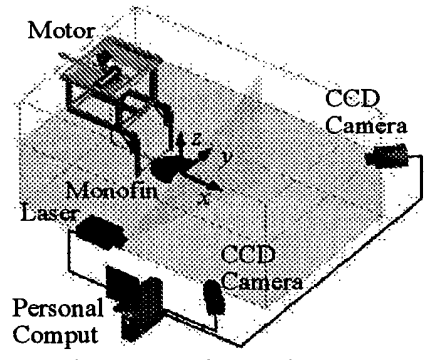

Fig. 2 Experimental apparatus for stereo PIV

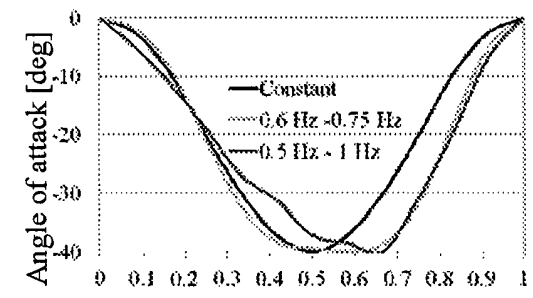

Non-dimensional time $t^{\prime}$

Fig.3 The temporal change of $\alpha$ during oscillating motion

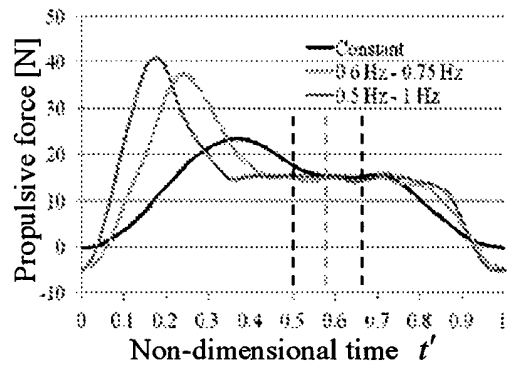

Fig.4 Propulsive force variations during one kick stroke 
はモータを制御している PC からの信号をパルスジェネレー タのトリガーとすることでフィンの動作と同期した. 三次元 的な渦構造は計測した各断面の渦度を繋ぐことで構築した。

\section{3. 推進力}

フィンの蹴り上げと蹴り下げ時の速度を変化させた際に 生じる推進力の計測を行った. 図 4 に躘り下げを速くした場 合の推進力の結果を示す.ここで $t^{\prime}=0$ はフィンが下死点の 位置である．図中の破線は各条件において，蹴り上げから蹴 り下げの位相に変化するタイミングを示している。一定速度 の場合，蹴り上げ時に大きなピークが生じる．蹴り下げを速 くした場合, 一定速度の場合よりもピークの值および一周期 中に得られる推進力が大きくなる。

\section{4.フィン後流の流れ場と三次元渦構造}

流れ場については，一定速度の場合と得られる推進力が最 も大きい踕り下げ速度が最も速い場合 $(0.5 \mathrm{~Hz}-1 \mathrm{~Hz})$ につ いて比較していく. 図 5 は $y=0 \mathrm{~mm}$ における $x-z$ 断面の速度 ベクトルと渦度場を示している. 図 5 の左図は一定速度の場 合, 右図は蹴り下げ速度が速い場合である. それぞれ推進力 がピークを示す時刻の流れ場である，一定速度の場合，蹴り 下げ時に生成された正の渦は下流に流され, 測定面内には確 認できない，一方，蹴り下げ速度が速い場合，蹴り下げ時に 生成された正の渦が測定面内に存在している.つまり，蹴り 下げと䟽り上げ時に生成された正，負からなる渦対がフィン の近くに存在している.この渦対が右斜め下方向に非常に強
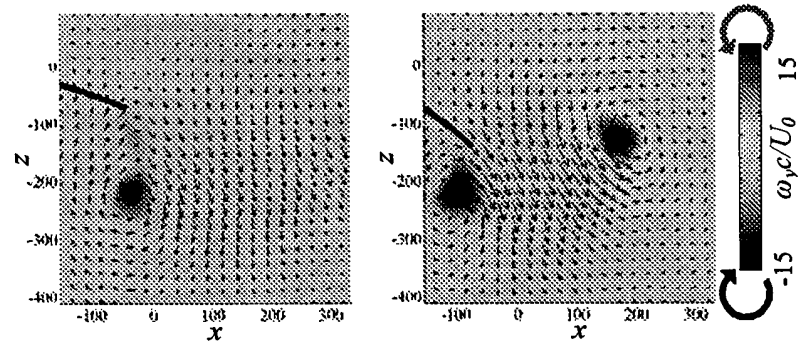

(a) Constant $\left(t^{\prime}=0.33\right)$

(b) $0.5 \mathrm{~Hz}-1 \mathrm{~Hz}\left(t^{\prime}=0.17\right)$

Fig. 5 Density map of vorticity and velocity vectors in the $x-z$ plane $(y=0 \mathrm{~mm})$

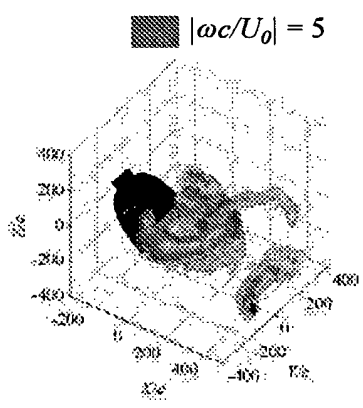

(a) $t^{\prime}=0$

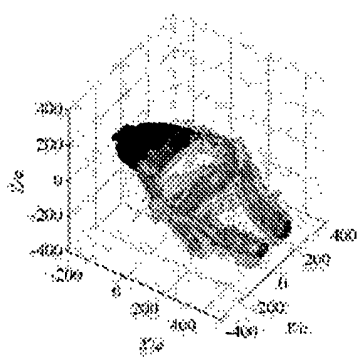

(c) $t^{\prime}=0.5$

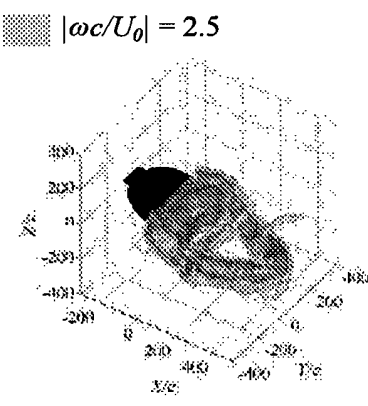

(b) $t^{\prime}=0.33$

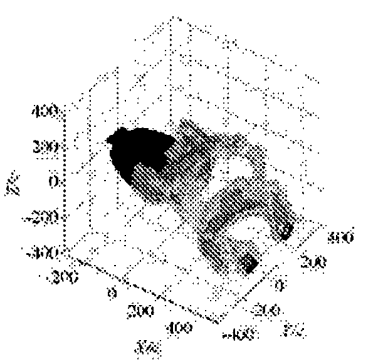

(d) $t^{\prime}=0.75$
Fig. 6 Three-dimensional vortex structure for constant kicking speed
い流れを誘起している．このため，殧り下げ速度が速い場合 の方がピークの值が大きくなる．図 6，7 はそれぞれ一定速 度の場合と蹴り下げ速度が速い場合の渦の三次元構造を示 している. 渦度の等值面を繋ぐことで三次元的な渦の構造を 構築している. 図中の赤色と黄色の領域は, それぞれ最大渦 度の $25 \%$ と $12.5 \%$ の渦度の等值面である. 一定速度の場合， 踭り上げ時にフィンの下面で渦が成長する(図 6(a)と(b)). $t^{\prime}=$ 0.33 において渦は放出されている(図 5(a)). その後, 蹴り下 げ動作になると，フィンの上面で渦が成長する。この渦は フィンの両端から下流方向に伸び，半円状に閉じている(図 6(a)). そして, 次の周期の蹴り上げ動作時にフィン下面で成 長する渦と連結し，一つの渦輪を形成する．この渦輪がフィ ンの後端から放出された後, 推進力が減少する. 䟽り下げ速 度が速い場合も同様に，踭り上げ時にフィンの下面で渦が成 長し， $t^{\prime}=0.17$ 付近で放出される(図 5(b)). また, 蹴り下げ 時になると, 蹴り下げ速度が速いため, 蹴り下げ動作の時間 が短くなる.このため, 一定速度の場合よりもよりフィンの 近傍で渦が成長する(図 7(a)). このため, 䟽り下げ時の速度 が速い場合，推進力は大きくなる.

\section{5. 結言}

フィンの振動中心を- $20^{\circ}$ として，蹴り上げと蹴り下げ速 度を変化させた際に生じる推進力と流れ場について調べた 結果をまとめると以下のとおりである.

1. 蹴り下げ時の速度が速い場合，一定速度の場合より， 推進力のピークの值および一周期中に得られる推進力 は大きくなる。

2. 蹴り下げ時の速度を速くすることで，蹴り上げ時にお いても渦輪をフィンの近くに留めることができる.こ の渦輪が強い流れを誘起し，推進力を大きく上昇させ る。また，蹴り上げ時に渦輪がフィンの後端から放出 される直前に推進力のピークが生じる。

引用文献

(1) N.Imamura et al., TFEC8, Incheon, Korea, 2013

(2)田村宏 ら, symposium on sportsengineering : symposium on human dynamics 2003, 32-35, 2003

(3)Jimmy Gautier et al., JSSM, (2004) 3, 91-95

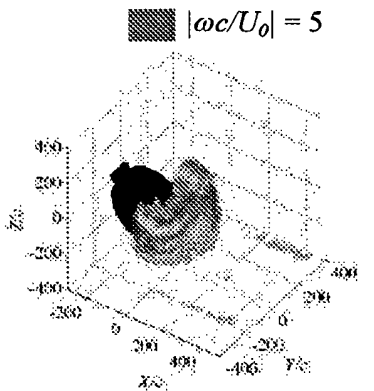

(a) $t^{\prime}=0$

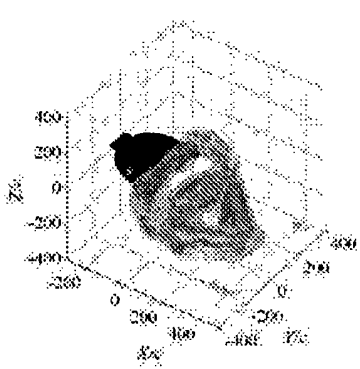

(c) $t^{\prime}=0.33$

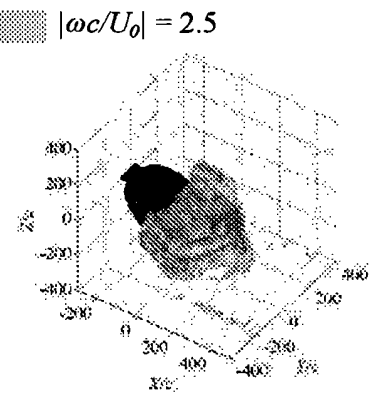

(b) $t^{\prime}=0.17$

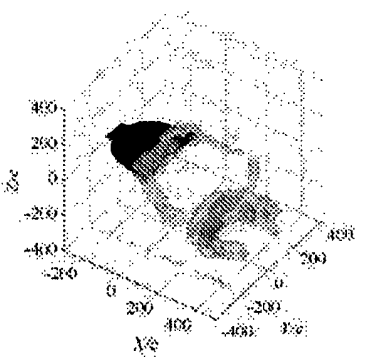

(d) $t^{\prime}=0.58$
Fig. 7 Three-dimensional vortex structure for the fast down-kick speed $(0.5 \mathrm{~Hz}-1 \mathrm{~Hz})$ 